\title{
Saneamento e política na Baixada Fluminense: Nova Iguaçu no início do século $\mathrm{XX}$
}

\author{
Sanitation and public policy in Baixada Fluminense territory: Nova \\ Iguaçu in the early twentieth century
}

http://dx.doi.org/10.5007/2178-4582.2014v48n2p282

Lúcia Helena Pereira da Silva

Universidade Federal Rural do Rio de Janeiro, Nova Iguaçu/RJ, Brasi

\begin{abstract}
A partir da criação da prefeitura de Nova Iguaçu, em 1919, é possível descortinar as várias disputas políticas existentes no grande município e uma imagem de Baixada Fluminense produto, entre outras coisas, da atuação de diversas Comissões de Saneamento que transformaram o tema insalubridade em principal chave de entendimento da região no período. O objetivo deste texto é analisar a criação da prefeitura como parte da história do saneamento na Baixada Fluminense, objeto de pesquisa do projeto intitulado "Baixada para os de baixo: aspectos do planejamento urbano na região metropolitana do Rio de Janeiro 1930/2000" que tem por finalidade, a partir da leitura do processo histórico de urbanização na região, analisar a atuação do Estado em suas múltiplas esferas (municipal, estadual e federal) em uma parte do território denominado, de uma forma geral, de Baixada Fluminense e, mais especificamente, no município de Nova Iguaçu.
\end{abstract}

Palavras-chaves: Comissões de Saneamento - Baixada Fluminense - Administração Pública - Nova Iguaçu
Through the creation of the Nova Iguaçu city hall in 1919 it is possible to present the some disputes existing politics in the municipality and the image of Baixada Fluminense, product of the performance of Sanitation Committees that had transformed insalubrity's subject into main key of knowledge of the region in the period. The objective of this paper is to analyze the creation of the city hall as part of the history of the sanitation of the Baixada Fluminense, state of Rio de Janeiro, object of the research called "Baixada for the Below: aspects of the urban planning in the region metropolitan of Rio De Janeiro 1930/2000"; that it has for purpose, to reading of the historical process of urbanization in the region, to analyze the performance of the State (as city, state and federal government) in the territory Baixada Fluminense, and more specifically in the city of Nova Iguaçu.

Keywords: Sanitation Committees - Baixada Fluminense - Public Administration - Nova Iguaçu

\section{Introdução}

Os discursos voltados para o saneamento da Baixada Fluminense tornaram-se potentes instrumentos de construção da imagem da região e, subsidiariamente, foram utilizados pelos grupos políticos do Estado do Rio de Janeiro e do município de Iguassu com a criação de sua prefeitura em 1919.

Articulando a história administrativa municipal aos discursos de saneamento voltados para a região, buscar-se-á articular esse repertório para dar 
inteligibilidade ao processo de instituição da prefeitura, da mesma forma que pontuar a força política das discussões em torno do tema da salubridade na Baixada Fluminense. O debate em torno do saneamento foi, e é, um potente "discurso competente" sobre a região, não só porque auxiliou a delimitação do que seria territorialmente a Baixada, mas porque consolidou e "naturalizou" uma forma de ler a região.

\section{Um pouco da história administrativa de Nova Iguaçu}

O município de Iguassu foi criado em 1833 no bojo da lei de $1^{\circ}$ de outubro de 1828. O novo município teve seu território composto de antigas freguesias do Termo da Cidade do Rio de Janeiro. A criação do município foi concomitante à criação da vila, sede da municipalidade. Mesmo reconhecendo a importância desse momento para a vida da municipalidade, principalmente porque dois anos depois o município seria extinto, voltando a ser restaurado em 1836, é a análise da legislação, ou seja, dos aspectos legais envolvidos na dinâmica da burocracia local, que será privilegiado para o entendimento da organização municipal, e não o processo político em si, ainda que este último seja levado em consideração. Esta opção é feita por duas razões: a primeira porque durante todo o Império o município manteve-se com a mesma organização administrativa; mas, principalmente, porque o período foge do escopo deste texto.

A lei de 1828, cujo título "Dá nova fórma ás Camaras Municipaes", marca suas "attribuições, e o processo para a sua eleição, e dos Juizes de Paz" (BRASIL, 1828). Essa lei procurou organizar o município através da Câmara Municipal, instância máxima do município, já que a edilidade exercia as funções de executivo e legislativo. A Câmara dividia com os juízes de paz toda a administração municipal. Para o que cabe aqui, vale ressaltar o artigo 66 que conferia à Câmara (legislativo) todas as atribuições de uma prefeitura (executivo). Essas perdurariam até a República.

\section{TITULO III}

\section{POSTURAS POLICIAES}

Art. 66. Terão a seu cargo tudo quanto diz respeito á policia, e economia das povoações, e seus termos, pelo que tomarão deliberações, e proverão por suas posturas sobre os objectos seguintes:

$\S 1^{\circ}$ Alinhamento, limpeza, illuminação, e desempachamento das ruas, cães e praças, conservação e reparos de muralhas feitas para segurança dos edificios, e prisões publicas, calçadas, pontes, fontes, aqueductos, chafarizes, poços, tanques, e quaesquer outras construcções em beneficio commum dos habitantes, ou para decôro e ornamento das povoações. 
$\S 2^{\circ}$ Sobre o estabelecimento de cemiterios fóra do recinto dos templos, $[. .$.$] ; sobre o esgotamento de pantanos, e qualquer$ estagnação de aguas infectas; sobre a economia e asseio dos curraes, e matadouros publicos, sobre a collocação de cortumes, sobre os depositos de immundices, e quanto possa alterar, e corromper a salubridade da atmosphera.

$\S 3^{\circ}$ Sobre edificios ruinosos, escavações, e precipicios nas vizinhanças das povoações, mandando-lhes pôr divisas para advertir os que transitam; $[\ldots]$

$\S 4^{\mathrm{o}}$ Sobre as vozerias nas ruas em horas de silencio, injurias, e obscenidades contra a moral publica. [...]

$\S 6^{\circ}$ Sobre construcção, reparo, e conservação das estradas, caminhos, plantações de arvores para preservação de seus limites á commodidade dos viajantes, $[\ldots]$

$\S 7^{\circ}$ Proverão sobre lugares onde pastem e descancem os gados para o consumo diario, em quanto os Conselhos os não tiverem proprios. [...]

$\S 9^{\circ}$ Só nos matadouros publicos, ou particulares, com licença das Camaras, se poderão matar, e esquartejar as rezes; [...]

$\S 10$. Proverão igualmente sobre a commodidade das feiras, e mercados, abastança, e salubridade de todos os mantimentos, $[\ldots]$

$\S 12$. Poderão autorizar espectaculos publicos nas ruas, praças, e arraiaes, uma vez que não offendam a moral publica, mediante alguma medica gratificação para as rendas do Conselho, que fixarão por suas posturas. (BRASIL, 1828, p.1)

A criação de Iguassu (1833-1836) ocorreu no momento de constituição de vários municípios, e esta pode ser pensada, seguindo as ideias de Oliveira (2003), na perspectiva da construção do Estado e da Nação como processos concomitantes. Nessa época, uma rede de indivíduos, com interesses diferenciados, ocupava posições políticas na Corte e nas províncias e, no exercício diário da política local, participavam da construção do Estado e de sua identidade política. A criação de Iguassu pode ser pensada nesta perspectiva, pois a atuação do grupo, capitaneados pelo Comendador Soares e pelo Barão do Guandu, não pode ser entendida sem as conexões que envolveram a instabilidade política da Regência, seja pela divisão dos diversos grupos (Jurujuba, Caramuru e Chimango) e pelas inúmeras revoltas; ou pela atuação dos cafeicultores de Vassouras e de políticos como o iguaçuano Marquês de Itanhaem, tutor de Pedro II. 
Grosso modo, e ainda que necessite de aprofundamento, pode-se dizer que o Município foi criado concomitantemente com a administração da província em $1834^{1}$, sendo que o governo municipal não tinha nenhuma autonomia. Ainda assim, durante todo o Império, Iguassu foi governado a partir de sua sede (Vila de Iguassu) pelos grandes proprietários e comerciantes locais, alocados na Câmara de Vereadores, a exemplo daquilo que Piñeiro denominou de "frações dominadas da classe dominante" (PIÑEIRO, 2006, p.82). Na década de 1830, o município era um dos mais prósperos da Província, na medida em que se especializara na logística de escoamento do café do Vale do Paraíba, o que se refletia na composição da Câmara.

A vila de Iguaçu, em 1848, tinha como presidente da câmara Manoel dos Santos de Andrade, negociante que acumulava as funções legislativas com as de delegado de Polícia. Os demais vereadores se distribuíam equilibradamente entre proprietários de terra e negociantes: no primeiro grupo, estavam os cafeicultores Bento Antônio Moreira Dias e Antônio Moreira Coelho Louzada, bem como Luiz Rodrigues Villares, fazendeiro em Jacutinga; no segundo, Ignácio Antônio de Souza Amaral, do ramo de "portos de receberem cargas a frete e a comissão", João Sabino Antônio Damasceno (da freguesia de Marapicu) e José Joaquim de Azeredo Coutinho. (MOREIRA, 2010, p.6)

Dois políticos dominaram a Câmara nos primeiros 30 anos, utilizando-a para garantir a hegemonia do grupo na região. Comendador Soares e Barão de Guandu eram grandes proprietários e comerciantes, ambos agiam dentro da Câmara e na Assembleia Provincial para a manutenção da estrutura econômica local que beneficiava o seu grupo.

Segundo o seu necrológio (S/A, 1874), o Comendador Soares era major da Guarda Nacional, além de proprietário da fazenda Morro Agudo onde plantava café e mandioca; possuía vários empreendimentos comerciais, entre eles padaria, porto (trapiche), de onde fazia frete fluvial, além de ser arrematante de barreiras (venda de bilhete de "ônibus") em sociedade com Jacinto Manoel de Souza e Mello, também vereador. Já Barão de Guandu foi o primeiro intendente do município; era proprietário da fazenda Olaria e dominou o transporte de carga pelos rios da região. Este era coronel comandante da Guarda Nacional.

Os dois sempre estiveram à frente de subscrições voltadas às melhorias da Vila, como a construção da igreja matriz, reforma das estradas e desobstrução dos rios. Duas ações podem ser utilizadas como exemplo da atuação do grupo na região. A primeira envolveu Comendador Soares, ao adiantar uma vultosa

\footnotetext{
${ }^{1}$ Até o ato Adicional de1834 a administração da província era feita pelo Ministério dos Negócios do Império.
} 
quantia ao governo provincial para melhorar as estradas de Iguaçu (RIO DE JANEIRO, 1837, p.53), das quais ele tinha o monopólio da venda de bilhete de "ônibus". A segunda foi o protesto da Câmara, capitaneada pelo Barão de Tinguá, contra a construção de uma ponte sobre o rio Iguaçu para a passagem da estrada de Ferro Norte (Leopoldina). A ponte era vista como obstáculo à navegação no rio, já em desuso em função da outra estada de ferro, a Pedro II, que tornara obsoleto o transporte fluvial (PEREIRA, 1970).

Tal como prescrevia a legislação ${ }^{2}$, a câmara municipal era composta de sete vereadores, já que o município tinha como sede uma vila (e não cidade). As atividades da câmara eram sazonais, e como os vereadores representavam o grupo hegemônico, mas de interesses heterogêneos, as disputas internas eram resolvidas na Tribuna Municipal, dependendo, entretanto, da composição da edilidade. Em 1848, quatro vereadores eram negociantes e três eram proprietários de terras.

No caso de Nova Iguaçu, é possível perceber, já na década de 1860, a disputa entre os proprietários e negociantes das áreas alagadas com os da terra firme. A freguesia de Piedade representaria os primeiros, enquanto Jacutinga representaria os segundos. A diferença entre as terras firmes e as alagadas não se fazia pela questão hídrica, já que as duas enchiam da mesma forma, mas pelo tempo que ficavam inundadas (se permanentemente ou periodicamente). As áreas próximas à baia eram dinâmicas porque concentravam a logística do escoamento de mercadorias, vindas do exterior e do interior, através dos rios e da baía de Guanabara, enquanto a terra firme era vista, então, como uma região secundária dentro da região.

A passagem da via férrea alteraria essa dinâmica, mas não a forma como eram resolvidas as disputas no interior do grupo dominante, já que a câmara se manteve com sete vereadores. A inauguração da Estrada de Ferro D. Pedro II, em 1858, viria dinamizar economicamente o pequeno povoado de Maxambomba na freguesia de Jacutinga, mas essa mudança seria lenta, embora a composição da câmara começasse a indicar e ratificar a nova correlação de forças, espacialmente identificada com a terra firme.

No ano da inauguração da ferrovia, o intendente do município era o cavaleiro da Imperial Ordem da Rosa e major da Guarda Nacional, Joaquim Inácio de Nascimento Faria, que, além de acumular o cargo de juiz de paz, era o substituto da vara dos órfãos e inspetor paroquial da freguesia de Piedade. Em 1862, era Inácio Antonio de Souza Amaral, já então Barão de Guandu

\footnotetext{
${ }^{2}$ Pela legislação eleitoral do período, as exigências de renda eram as seguintes: 200 mil réis para ser apenas votante (não elegível); 400 mil réis para ser eleitor (votar nas eleições secundárias), juiz de paz e vereador; 800 mil réis para ser deputado e 1.600 mil réis para ser senador. A Câmara Municipal compunha-se de sete vereadores se a sede do município fosse uma vila e de nove se a sede fosse uma cidade.
} 
(desde 1856), rico comerciante e proprietário na freguesia de Piedade (Almanak,1866, p.218). Piedade, e em menor grau Palmeiras, representavam, dentro do município, a dinâmica econômica das terras alagadas, aquelas voltadas para a logística de escoamento do café pelos rios e a baia.

Em 1866, o colégio eleitoral do município era formado por 56 eleitores. Destes, 17 estavam em Piedade, 15 em Marapicu, 12 em Jacutinga e seis em Palmeiras e em Meriti (ALMANAK, 1866, p. 63). Naquele ano, o intendente era o capitão Francisco Pinto Duarte, rico comerciante de Piedade. A gestão, que findaria em 1867, não tinha nenhum representante de Jacutinga, mas três de Marapicu. Apesar de Piedade possuir o maior número de votantes, Maripicu, Meriti ${ }^{3}$ e Jacutinga eram identificadas com a dinâmica da terra firme; juntas, detinham a maioria dos eleitores.

Em 1870, o Comendador Soares era o intendente. Piedade elegera apenas dois vereadores, Palmeiras contava com um, e os demais vinham das outras freguesias. Embora essa situação possa ser pensada como tendência, principalmente porque mais tarde aconteceria a transferência da sede do município para Maxambomba que, entre outras coisas, ocorreu em função da decadência econômica da Freguesia de Piedade onde estava situada a vila de Iguassu, a passagem do Império para a República não mudaria a estrutura administrativa de Iguassu, já que a câmara continuou atuando como prefeitura.

Durante todo Império, dentro do município não houve separação da esfera política da administrativa. A câmara não tinha autonomia e dependia do governo provincial, inclusive para ratificar as deliberações aprovadas por ela e controlar rigidamente as rendas arrecadadas. Desta forma, desde as posturas municipais até a execução das obras locais passavam pela aprovação do governo provincial. $\mathrm{O}$ intendente ou presidente da mesa era o vereador eleito entre eles, e atuava como voto de desempate.

Sem autonomia, a câmara se reunia quatro vezes por ano em pelo menos seis sessões ordinárias ou, quando necessário, de forma extraordinária. Ainda faltam pesquisas para saber se a câmara municipal se reunia, como na maioria dos municípios fluminenses, em duas sessões ao mês, mas pode-se dizer que a principal função da câmara era fazer petição ao governo provincial, informando a arrecadação dos impostos, dos gastos realizados e solicitando permissão para a execução de obras. Somente em 1870, o governo provincial passaria a distribuir uma renda entre os municípios.

A câmara estava organizada da seguinte forma: um secretário, um procurador, um porteiro, um contínuo, um estafeta, fiscal do fisco em cada uma das freguesias, um médico e trabalhadores do cemitério (ALMANAK, 1858,

\footnotetext{
${ }^{3}$ Naquele momento não era área correspondente a Duque de Caxias, que pertencia ao município de Estrela
} 
p.102). Tendo pouca autonomia, e dependente do governo imperial, as principais ações foram pensadas a partir da ótica de "desenvolvimento regional", e não local, como esclareceu o presidente da província em 1835, ao relatar à assembleia provincial sobre a atuação do engenheiro Conrado Jacob Niemayer na região para a confecção da carta topográfica e do conjunto de obras que estava sugerindo para Iguassu:

\begin{abstract}
Notarei que as incontáveis vantagens de semelhante melhoramento não têm que reverter somente sobre a florescente povoação de Iguassu, senão também em beneficio dos fazendeiros e moradores de Serra acima que enviam seus produtos ao grande mercado do Rio de Janeiro. A maior parte dos que descem pelas freqüentadas estradas do Comércio, Policia, Rodeio, em vez de seguirem por terra, encontram maior conveniência em dirigirse ao Porto de Iguassu, por ser mais cômodo e talvez menos dispendioso o transporte por mar feito dentro da baia de Nictheróy...(RIO DE JANEIRO, 1836, p.47)
\end{abstract}

Apesar de ser região estratégica para o escoamento do café, na medida em que, em 1857 Iguassu era o segundo porto da província, o município era totalmente dependente dos recursos do governo provincial. Um ano antes da inauguração da estrada de ferro, a preocupação do presidente de província com o porto mostrava, avaliando dentro de uma "visão de desenvolvimento regional", o impacto negativo que o trem teria para a dinâmica comercial do porto.

$2^{\circ}$ porto de Iguassu - é de certo o segundo mais importante da província como porto comercial, a sua exportação para a corte foi no ultimo triênio a seguinte:

\begin{tabular}{|c|c|c|c|c|}
\hline Anos & Café & Feijão & Farinha & $\begin{array}{l}\text { Tapioca } \\
\text { e outros } \\
\text { generos }\end{array}$ \\
\hline 1854 & $\begin{array}{c}1: 886,306 \\
\text { arrob }\end{array}$ & 58 sacas & 141 sacos & 7,025 sacos \\
\hline 1855 & $1: 821,742$ & 194 “ & 197 & 9,735 “ \\
\hline 1856 & $2: 192,168$ & 221 “ & 55 & 11,417 ، \\
\hline
\end{tabular}

A importação em valor excede a 1,600:000\$000. Quase todos os gêneros exportados são produzidos pelos municípios de Iguassu, Vassouras, Valença, Paraiba do Sul e alguns outros circunvizinhos da nossa província e da de Minas Gerais, que descem ao porto pelas estradas do Comércio, Verneck, Policia e Presidente Pedreira. A navegação é feita com demora em consequencia da parte superior do rio, aonde está assentada a vila, e do mau estado da barra; emprega-se nela 24 lanchas de dois mastros carregando cada uma de 2 a 3 mil arrobas, 
além de muitos saveiros: navega constantemente além disso muitos barcos, que exportam lenha, tijolo, telha e outros artigos produzidos pelo município. Este porto tem muito de decair logo que funcione a estrada de ferro Pedro II" (RIO DE JANEIRO, 1857, p.68-67, grifos meus)

Ainda que preliminar, é possível dizer que durante o século XIX, a câmara funcionou de forma dependente do governo provincial, que se organizava em torno de suas quatro grandes diretorias (instrução, obras, fazenda e governo), atuando na região no sentido de conciliar as demandas locais às regionais. A assembléia provincial era o espaço onde as demandas poderiam ser satisfeitas. Inicialmente Iguassu fazia parte do colégio eleitoral de Itaguaí (com direito a cinco assentos), mas, com a reforma de 1856, o município passou a fazer parte da comarca de Vassouras.

Segundo Gouveia (2008), a assembléia provincial, a partir dos anos de 1850, passou a definir um conjunto de prioridades; entre elas, estavam o transporte e a saúde, um para que pudesse garantir na província a integração da malha viária, o outro, no sentido de resolver o problema das epidemias que, apesar de recorrente, ainda não era acionada como instrumento de leitura para entendimento da região ou mesma vista como questão social. A partir dos anos de 1870, essa situação mudaria em função do dinamismo que a passagem da estrada de ferro D. Pedro II imprimiria nas terras da Baixada.

Ao longo de todo Império, a câmara dos vereadores atuou como legislativo e executivo. Como legislativo, era espaço de negociação da classe dominante local e, como executivo, apenas implementava as obras definidas e financiadas pelos governos provinciais, produtos de forças e políticas mais amplas.

\section{Saneamento como o discurso da região da Baixada Fluminense.}

Até a década de 1870, os relatórios dos presidentes de províncias davam conta das epidemias de febre amarela, cólera, malária e varíola que grassavam a província em seus diversos municípios, mas não associavam diretamente a proliferação das doenças à degradação do meio ambiente, ainda que relacionassem, de forma tênue, as áreas alagadas ao desenvolvimento das febres, como apontava o conselheiro Joaquim José Rodrigues Torres, em 1835:

A câmara da Vila de Magé, cujo Termo é um dos mais sujeitos a perniciosa influência das febres, solicitou do Ministro do Império em agosto do ano próximo passado meios precisos para a abertura de vários canais ou valas, que dessequem as terras pantanosas do seu município, e cuja despeza fez a câmara chegar a soma de reis 48:000\$000. Se estas obras são eficazes para fazer daqueles lugares desaparecer as febres perniciosas que flage- 
lam, é questão que me não parece ainda inteiramente resolvida, mas a consideração que não semelhante obras restituirão à agricultura porções de excelentes terreno, mas ainda que de certo concorrerão para minorar a força da enfermidade [...] (RIO DE JANEIRO, 1835, p. 9, grifos meus)

Em 1840, o presidente da província afirmava que a mortalidade causada pelas inúmeras epidemias estava associada à falta de estrutura da saúde pública, ou seja, para ele, não eram as condições ambientais que facilitavam a propagação das doenças, mas as condições sociais, já que essas enfermidades afligiam sempre os mais pobres. Para ele, as doenças estavam associadas à pobreza e à desorganização da administração pública, tal como ilustra a passagem abaixo.

\begin{abstract}
$\mathrm{Eu}$ vos farei remeter os numerosos e interessantes documentos de onde extrai o que acabo de expor. Neles encontrareis muita particularidades e observações peculiares da ciência médica e relativa às causas que produzem ou aumentam os funestos efeitos do fenômeno devastador, que em alguns anos anteriores tanto flagelou alguns pontos das partes baixas e paludosa da província.
\end{abstract}

Posso todavia assegurar-vos que a mortalidade que tem causado geralmente provem da falta de tratamento. A experiência tem pois mostrado que o flagelo das febres endêmicas procura a maior parte das suas vitimas entre as classes privadas pela miséria, pela indolência ou ignorância de adequados recursos. (RIO DE JANEIRO, 1840, p.13, grifo meu)

Paulino José Soares de Souza, assim como outros políticos da época, explicitavam um conhecimento médico que circulava na sociedade acerca das principais causas das doenças endêmicas que assolavam a região. Não havia consenso entre os médicos, apesar de todos associarem de alguma forma a existência das águas paradas à proliferação das doenças; ainda assim, não se fazia uma relação direta entre o meio ambiente e a propagação das febres, já que muitos achavam determinante na circulação das doenças a condição social dos habitantes.

Ao longo das décadas de 1840 e 1850 , os relatórios se reportavam à pouca vacinação e aos socorros financeiros nos momentos de crise. O município sofria com a cólera e a varíola, que antes ficavam restritas às áreas ribeirinhas; com a passagem da via férrea na região de Jacutinga, as rotas internas foram criadas e as antigas dinamizadas, transformando-as também em vetores de propagação das doenças. O trem incrementava o uso das vias vicinais à estação. Seriam essas estradas, juntamente com os rios e os pântanos, os prin- 
cipais propagadores das inúmeras epidemias da região como varíola, cólera e malária.

Desde os anos de 1840, os vários presidentes de províncias destacavam a necessidade de drenagem dos pântanos, ainda que não se fizesse uma relação direta de causa e efeito entre áreas alagadas e as febres, inclusive, desde 1857 (Decreto 1071 de 14/11/1857), o governo cobrava um imposto destinado especificamente ao dessecamento dos pântanos, mas "Iguassu, apesar de seu prestígio no seio da província assustava por suas febres tão constantes quanto fatais" (TORRES, 2004, p.184), não possuindo hospital, apenas um médico vacinador, a falta de estrutura de saúde era vista pelos presidentes da província como o principal problema para o controle das epidemias.

Em 1870, o governo provincial reorganizou Diretoria de Obras, dividindo-a em 11 distritos, cada um deles com um engenheiro e um auxiliar, de forma a dar agilidade nas obras, cada distrito passaria a ter mais autonomia. Iguassu juntamente com Itaboraí e Mangaratiba formavam o $9^{\circ}$ Distrito (RIO DE JANEIRO, 1870, p.35), mas com área extensa e necessidades diferentes, essa nova divisão não dinamizou a consecução das obras necessárias ao município, principalmente porque o distrito era grande e a dupla não dava conta das diversas demandas.

Ao lado das mudanças na administração da província, a partir da década de 1870 , o estado imperial investiria em projetos e estudos de dragagem dos rios da região, além dele próprio, através de suas repartições, atuar no dessecamento das áreas alagadas. A primeira ação de que se tem notícia deu-se em 1870, sob a breve gestão provincial de Teodoro Machado Freire, com a dotação de recursos para limpar e canalizar vários rios da região, entre eles o Caioaba e o Bonga, além de aterrar os pântanos de Belém, atual Japeri, várzea do Guandu (TORRES, 2004).

Segundo Telles (1994), na prática, nenhuma ação havia sido estabelecida na região para resolver o problema dos alagamentos e das doenças palustres, mas é importante destacar que, nos anos de 1870, uma nova forma de pensar a questão da insalubridade começava a ser gestada. O ministro dos negócios do Império, em seu relatório anual, naquele ano informava que a Academia de Medicina e a Junta de Higiene apresentaram um estudo apontando que a proliferação das doenças na Corte devia-se à existência de terrenos pantanosos em diversos pontos da cidade e, em função disso, ele estava destinando recursos para drenagem nas áreas suburbanas.

Sendo ainda freqüente esses terrenos baixos e alagados, principalmente nos subúrbios da cidade, entendo que cumpre destinar no orçamento a meu cargo, por adiantamento e pelo modo a 
que acabo de referir-me a quantia de 200:000\$000 anualmente pelo menos para se ir levando a efeito o desaparecimento de tão perniciosos focos pestilenciais (BRASIL, 1871, p.90).

A imagem de região insalubre foi produzida discursivamente a partir da relação direta entre a existência das áreas pantanosas e a disseminação das doenças. Essa articulação não era consenso entre os médicos no início do século $\mathrm{XIX}^{4}$, mas se tornara consensual na década de 1870 , não só sendo reproduzido como argumento do ministro para legitimar a dotação de verba para os dessecamentos das áreas dos subúrbios da Corte, como também passaria a ser utilizado para a formação de inúmeras comissões de estudos sobre a Baixada e outras localidades da província do Rio de Janeiro.

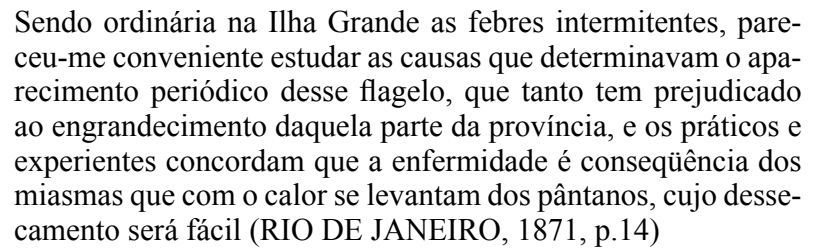

Segundo Telles (1994), em 1883 foi constituída uma comissão chefiada pelo engenheiro major Rangel de Vasconcelos para estudar a melhor forma de dessecamento das áreas pantanosas. $\mathrm{O}$ estudo foi entregue ao ministro do Império com sugestões de obras; mas, consideradas dispendiosas, não saíram do papel. Entretanto, esse estudo associou as enchentes às epidemias e consolidou uma forma de leitura e entendimento da região.

A partir daí, principalmente por onde passava a via férrea, a região seria objeto de estudos dos engenheiros, sempre associando a necessidade de drenagem como forma de minimizar a propagação das doenças que sempre assolaram Iguaçu. Foi durante uma epidemia de varíola que a sede do município foi transferida da velha Iguassu para Maxambomba.

Tabela 1 - População de Iguassu entre 1890 e 1920

\begin{tabular}{lrcrrrr}
\multicolumn{1}{c}{ Local/Ano } & \multicolumn{3}{c}{$1890^{*}$} & & $1920^{* *}$ \\
\hline & Homem & Mulher & total & Homem & Mulher & Total \\
\cline { 2 - 7 } Município de Iguassu & 10.019 & 9.690 & $\mathbf{1 9 . 7 0 9}$ & 17,707 & 15.689 & $\mathbf{3 3 . 3 9 6}$ \\
Jacutinga*** & 3.316 & 3.248 & $\mathbf{6 . 5 6 4}$ & 6.456 & 5.926 & $\mathbf{1 2 . 3 8 2}$ \\
\hline
\end{tabular}

Fontes: * Censo de 1890. Brasil, 1898

** Censo de 1920. Brasil 1922a

*** A freguesia de Jacutinga denominava-se em 1920, Distrito Sede de Iguassu

${ }^{4}$ Sobre essa discussão, ver Silva (2012) em especial o capítulo 2. 
Maxambomba chegava à República como um povoado, com as duas quadras em torno da estação ocupadas de lojas e um comércio variado, embora fosse eminentemente rural, tendo o cultivo de laranja como a sua maior atividade econômica. Segundo Mattos,

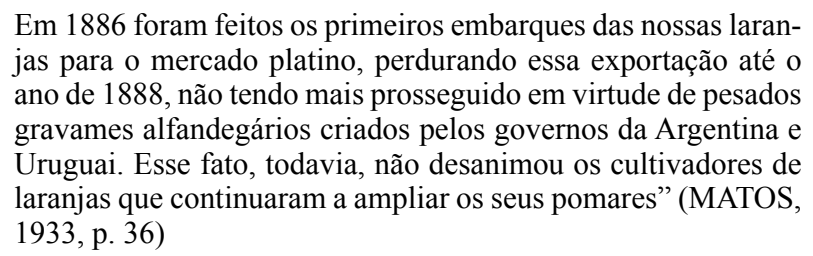

Com a República, o município de Iguassu passaria a ter como sede o povoado de Maxambomba, rapidamente alçado ao status de cidade, em 1891. A freguesia de Santo Antonio de Jacutinga, naquele momento, transmutada de $1^{\circ}$ Distrito (Distrito Sede), possuía 6.564 habitantes, a maioria negra (62,29\%). A passagem do Império para República e a transferência da sede do município não interromperam a atuação do governo central nas designações de engenheiros para a confecção de estudos para a região.

Entre 1891, ano da mudança da sede do município, e 1919, momento de constituição da prefeitura, várias comissões foram instituídas pelos governos federal e estadual para estudo sobre saneamento e obras na Baixada. Nesse período, o engenheiro Marcellino Ramos da Silva foi um nome de destaque 5 .

Em 1894 foi criada a Comissão de Estudos e Saneamento da Baixada pelo governo estadual. Essa comissão foi chefiada inicialmente pelo engenheiro João Teixeira de Soares, depois assumindo o $1^{\circ}$ engenheiro da comissão, Marcellino. Segundo Telles (1993), em seus seis anos de existência pouco se tem notícia de suas ações, e com a sua extinção uma outra comissão foi formada, mas essa era particular, fruto de concessão do estado. Tinha como objetivo dessecar as terras alagadas para a utilização da agricultura; mas também isso não saiu do papel.

Em 1910 foi instituída a Comissão Federal de Saneamento da Baixada, chefiada inicialmente por Marcellino ${ }^{6}$ e, depois, pelo engenheiro Fábio Hostílio de Moraes Rego. Essa comissão trouxe profundas transformações para o entendimento dos problemas de insalubridade da região. Em termos práticos, a comissão realizou algumas obras de dragagem nos rios Estrela, Suruí, Iriri, Magé e Macuco, não atuando na região por onde passava a via férrea Cen-

\footnotetext{
${ }^{5}$ Foi membro da comissão do plano de melhoramento da cidade do Rio de Janeiro, juntamente com Pereira Passos e Jerônimo Jardim. Sobre a atuação do engenheiro na comissão, ver Silva (2012).

${ }^{6}$ Marcellino faleceu em 25 de dezembro de 1910.
} 
tral do Brasil (antiga D. Pedro II). Ao longo de seus seis anos de existência, a comissão foi importante porque consolidou uma nova forma de pensar e, consequentemente, de agir dos engenheiros em relação aos problemas de insalubridade na Baixada.

A proposta de saneamento defendida pela comissão apontava a salubridade como instrumento de desenvolvimento econômico regional, pois potencializaria a ocupação territorial atraindo maior contingente populacional, além de diminuir a mortalidade da população local. Essa nova leitura se diferenciava daquela que se assentava nos paradigmas da Higiene da Medicina Social, principalmente por articular saneamento à modernização do território.

A modernização estava na agenda republicana, na qual os engenheiros tornaram-se sujeitos privilegiados porque modernização era vista como transformação da estrutura material, principalmente a produtiva. Ainda que concorressem com os médicos, no que tange à ideia de saneamento como política de saúde pública, a engenharia ratificou seu campo disciplinar e profissional ao se colocar como protagonista para organizar eficazmente o meio, visando saneá-lo, agindo como autênticos "missionários do progresso" (HERSCHMANN; KROPF; NUNES, 1996).

A comissão chefiada por dois engenheiros advindos da Escola Central do Exército ratificou a relação existente entre saneamento e a extinção das formas de propagação das doenças que sempre assolaram a região; mas, diferente das comissões anteriores, não se restringiu ao problema das enchentes, tendo uma visão mais ampla da região, tal como defendia a ementa da disciplina de economia política que os dois engenheiros cursaram? ${ }^{7}$.

A Comissão explicitava o ideário que conjugava desenvolvimento econômico e saneamento, seu objetivo era tornar as terras da Baixada aptas a serem exploradas economicamente e, para isso, a região necessitava ser ocupada. Saneamento, para os engenheiros da comissão, era o caminho encontrado para a erradicação das doenças e garantir o seu povoamento já que a Baixada era vista como um vazio, um sertão. O progresso viria pela ocupação e pelo desenvolvimento de diversas atividades econômicas na região.

É importante salientar que essa comissão foi instituída no curto período em que Nilo Peçanha foi presidente da república (1909/10); e ao longo de sua vida política sua atuação na Baixada realizou-se em duas frentes, aparentemente antagônicas: ao mesmo tempo em que se preocupava com a existência das terras devolutas e as condições em que se encontravam os muitos fazen-

\footnotetext{
${ }^{7}$ Essa disciplina foi introduzida na reforma de 1863, produto de intenso debate na Câmara dos Deputados onde o futuro Visconde do Rio Branco, professor da EC foi ardoroso defensor da inserção de uma cadeira voltada aos "estudos sociais". Sobre isso, ver Telles (1993).
} 
deiros arruinados, corroborando, assim, o dueto saneamento-povoamento defendido pela engenharia, ele também foi um dos artífices da ocupação urbana na estação Engenheiro Neiva (Nilópolis), ao patrocinar a instalação dos sistemas de água e de luz, agência do Correio e construir as pontes que ligavam a localidade ao Rio de Janeiro e à Nova Iguaçu (CARDOSO, 1938).

Após a existência de várias comissões, um discurso sobre a Baixada estava consolidado, não só onde o processo de urbanização estava ocorrendo com celeridade (atuais Caxias e Nilópolis), mas para toda a região, tendo saneamento como a principal ação de recuperação do território, garantindo a salubridade que induziria a ocupação territorial e o desenvolvimento econômico. Em torno desse discurso, criado no espaço das comissões, os grupos políticos do Estado do Rio e do Município de Iguassu disputaram a criação da prefeitura em 1919.

Saneamento como instrumento de jogo político: a criação da prefeitura de Iguassu

Segundo Pereira (1970, p.108), "a criação da prefeitura municipal de Nova Iguaçu foi um caso rumoroso e apaixonante, cheio de lances curiosos e arrebatados". Para o autor, a população de Nova Iguassu - que desde 1916 deixara de denominar-se Maxambomba - demandava a instalação de rede de esgoto na cidade e melhoria na distribuição da água, mas o governo municipal não tinha condições financeiras para realizá-las, apesar do crescimento da exportação das laranjas.

Para o que cabe aqui, e sem aprofundar o estudo do intrincado jogo político que envolveu a criação da prefeitura, é possível destacar que o Decreto 1.614 de 29 de outubro de 1919 autorizava o governo estadual a dispor de recursos para instalar redes de esgoto em municípios que não tivessem condições financeiras para tal, e em lugares onde não existisse prefeitura, a contrapartida seria a sua criação para que o governo estadual pudesse nomear um interventor e com isto controlar o uso do recurso.

O município de Iguassu se mantinha ainda com a câmara exercendo as duas funções (legislativo e a executivo); os políticos locais leram o decreto como uma forma de intervenção nos assuntos municipais, tal como exposto na primeira sessão ordinária depois da promulgação do decreto.

[...] O vereador Peregrino Esteves de Azevedo fazendo uso da palavra, protestou sobre a intromissão do Estado nos negócios do município e analisando a lei 1614 de 29 de outubro do corrente ano, diz que aludida lei em seu artigo 11 vem ferir exclusivamente a autonomia do município de Iguassu, mo- 
tivo porque como representante do povo iguassuano lavra o seu protesto e submete a apreciação dos seus colegas o projeto seguinte: a câmara municipal de Iguassu, artigo 1 fica o presidente da câmara autorizado a fazer a rede de esgoto, artigo 2, podendo desde já afixar editais chamando concorrente, artigo 3 Fica também o presidente da câmara autorizado a contrair empréstimos para a realização dos aludidos serviços, artigo 4 Definindo (?) para isso os sucessivos créditos, artigo 5 revogam-se as disposições em contrário [...] (CÂMARA MUNICIPAL DE NOVA IGUAÇU, 1919, p.33)

Independente do protesto da Câmara, o governo estadual criou a prefeitura e nomeou o médico Mario Pinotti para prefeito, fazendo com que a edilidade impetrasse um habeas-corpus para impedir que o interventor continuasse no executivo municipal. Segundo Pereira (1970), a morte do Coronel Soares, líder político contrário à criação da prefeitura, enfraqueceu o grupo local, permitindo, então, que o executivo fosse separado do legislativo.

\begin{abstract}
Naquele ano, em agosto (1920), morria o presidente Ernesto França Soares, quando caçava em xerém, vitima de um mal súbito que o derrubou do cavalo ao chão. Com França Soares desaparecera o calor da resistência. O cel. Alberto de Melo exilou-se na Guanabara (onde faleceu recentemente) e Mario Pinotti ficou sendo o primeiro prefeito iguaçuano (Pereira, 1970, p.115)
\end{abstract}

Sem adentrar na disputa política que envolveu o grupo local e o estadual cuja influência se remetia a Nilo Peçanha, é importante ressaltar que a escolha do médico sanitarista Mario Pinotti ocorreu em função da sua atuação em uma comissão de saneamento, justamente porque o argumento utilizado para a criação da prefeitura era a instalação da rede de esgoto no local. O médico foi indicado, nas palavras do presidente do estado, por ser um profissional competente e distante das disputas políticas, corroborando a idéia de que a neutralidade técnica seria suficiente e eficiente para a condução da vida pública e da política local.

É mister, porém, ao restituirmos o direito de escolha por sufragio direto, do seu órgão executivo, ampliar-lhes o campo em que esse direito se possa exercitar. Entre os requisitos da elegibilidade para o cargo de prefeito, não convém exigir-se o da residência no município: facilitemos a investidura nesse cargo de quantos possam bem exercê-lo, sem aquela restrição, que faria depender o interesse da administração das condições inerentes a acanhados meios, onde não se encontrariam os melhores candidatos, dos quais se deve exigir, ao lado da competência técnica, a indispensável isenção de animo em face das competições locais. (RIO DE JANEIRO, 1920, p. 14-15, grifo meu) 
No mesmo ano, foram criadas duas comissões federais voltadas ao saneamento da região, a primeira dos engenheiros, sob a alçada do Ministério da Viação e Obras Públicas, e a segunda dos médicos, sob a tutela do Ministério da Justiça e do Interior em conjunto com o governo estadual. Foi na segunda comissão em que o médico Pinotti estava alocado quando foi nomeado ao cargo de prefeito.

Independente do que foi realizado pelas duas comissões, dois aspectos devem ser ressaltados. Enquanto uma estava voltada à execução de obras de dessecamento das áreas alagadas, a outra se centrava na profilaxia das doenças. A comissão dos engenheiros, denominada de "Saneamento da Baixada", chefiada por Tobias L M Moscoso e, depois, por João Baptista de Moraes Rego, assim como antigas comissões, pouco fez na extensa região que tinha sob alçada; já a comissão dos médicos era mais atuante, principalmente porque o seu objetivo era diminuir drasticamente as doenças nas áreas suburbanas do Distrito Federal. A região de Iguassu foi contemplada porque era muito próxima da capital do país, tal como exposto na mensagem do presidente do estado.

\footnotetext{
Os trabalhos de saneamento, na parte da profilaxia rural, foram contratos, com o Governo Federal, por acordo realizado com então ministro do Interior, Dr. Urbano Santos e confiados ao Dr Belisario Pena, que superintendia os relativos ao Distrito Federal; com a Rockefeller Fondation, em virtude de autorização votada por essa assembléia, além de outros que estão sendo efetuados diretamente pela Diretoria Geral de Obras Públicas

Iniciados os serviços afeitos ao Governo federal, no principio do segundo semestre de 1919, foram logo criados postos sanitários de Merity, São João de Merity, Queimados e Itaguaí [...]
Para maior eficiência do serviço de pronto socorro e tratamen- to dos doentes, foram estabelecidos subpostos em Queimados, Paracambi e José Bulhões, dependentes de Nova Iguassu; em Jerônimo Mesquita, dependente de Anchieta; na Raiz da Serra, dependente de Merity, na ilha da Madeira, dependentes do de Itaguai (RIO DE JANEIRO, 1920, p. 37).

A estrutura administrativa à qual estava alocada fez da comissão de "Profilaxia Rural" um grupo mais eficiente do que o dos engenheiros, principalmente por ter mais recursos financeiros. Enquanto na mensagem de 1920, o presidente de estado contabilizava o sucesso da atuação dos médicos na região, o ministro de Viação e Obras Públicas fazia o histórico do fracasso da comissão, herdeira daquela de 1910.

Essa segunda proposta, que mais tarde foi aplicada,estava ainda pendente de solução, quando em meados de 1920, foi apresen- 
tado ao governo um plano para execução dos melhoramentos da Baixada, segundo um projeto original e em regime de concessão tendente a exonerar o governo das despesas de sua execução $[\ldots]$

Corrigindo, desde então, os detalhes da combinação, sob a imediata assistência de V Ex e de acordo com o autor do plano e proponente, que então tomara a si o antigo contrato de 1910 , chegou-se finalmente a uma formula definitiva, que foi consubstanciada no contrato aprovado, o qual satisfaz plenamente aos interesses do governo, que pode assim promover, sem despesa alguma, a execução de grandes obras públicas, de real utilidade e no valor de muitos milhares de contos (BRASIL, 1922 b, p.300-303) .

O segundo aspecto da atuação dessas comissões está relacionado com a própria criação da prefeitura, na medida em que o argumento utilizado foi o do saneamento, e a escolha do médico não deixou dúvida quanto à "potência de verdade" do discurso produzido acerca da (e disseminado na) região. A imagem construída, dentro e fora da Baixada, criou um solo comum onde se desenrolariam as disputas políticas e as leituras do que seriam os problemas do município - ainda imensos- pois comportava os atuais municípios de Duque de Caxias, Belford Roxo, Mesquita, Nilópolis, Queimados, Japeri e São João de Meriti.

Engenheiros e médicos transformaram, discursivamente, a Baixada. Em lugar de doença e vazio populacional, esta imagem foi construída a partir da atuação das várias comissões que passaram pela região depois de 1870. Contraditoriamente, ao mesmo tempo em que era vista como sertão, portanto, espaço a ser ocupado e desenvolvido economicamente, estava muito próxima da capital do país, cujo centro já estava saneado e incorporado às "luzes do progresso", faltando, então, à sua área contígua (subúrbio e periferia) seguir o mesmo destino.

Sem aprofundar a discussão sobre a atuação da comissão onde estava alocado o prefeito, é importante destacar que o médico foi alçado ao posto de executivo municipal de Iguassu com pouco tempo de exercício profissional na região, exatamente por encaixar-se no perfil político desenhado pelo governo do estado. Foi escolhido para ser o novo interventor, entre outras coisas, porque era um profissional que trabalhava na Baixada com saneamento.

Saneamento era visto como condição primordial para a realização do progresso econômico e social da região, situação sine qua non para o povoamento e aceleração de duas dinâmicas territoriais que já ocorriam em Iguassu: ocupação urbana desordenada (nas estações de Engenheiro Neiva - atual Nilópolis, 
São João de Merity e Merity - atual Duque de Caxias), e desenvolvimento agrícola (citricultura na área que hoje compreende Nova Iguaçu, Mesquita, Belford Roxo e Queimados).

Essas duas dinâmicas auxiliaram a constituir as duas centralidades urbanas da Baixada, a de Nova Iguaçu e a de Duque de Caxias, e estas foram patrocinadas pela atuação das diversas comissões de saneamento que passaram pela região. Ainda haveriam outras comissões voltadas ao saneamento, mas a imagem de vazio, de lugar das febres "à espera de progresso" estava consolidada, mesmo já com áreas densamente ocupadas e a citricultura em expansão.

Depois de 1919, o grande município de Iguassu (só na década de 1930 passaria a ser denominado de Nova Iguaçu) encontrava-se organizado com as funções executivas e legislativas separadas e o território ainda necessitando de saneamento. Seria a imagem consolidada de região insalubre que potencializaria, anos mais tarde, o surgimento da mais famosa comissão da Baixada, a do engenheiro Hildebrando de Goes, em 1933, inaugurando um novo capítulo de intervenções na região. $\mathrm{O}$ discurso do saneamento permitiu, entre outras coisas, a intervenção do governo estadual no município através da criação da prefeitura.

Figura 1 - Município do município de Nova Iguaçu em 1920

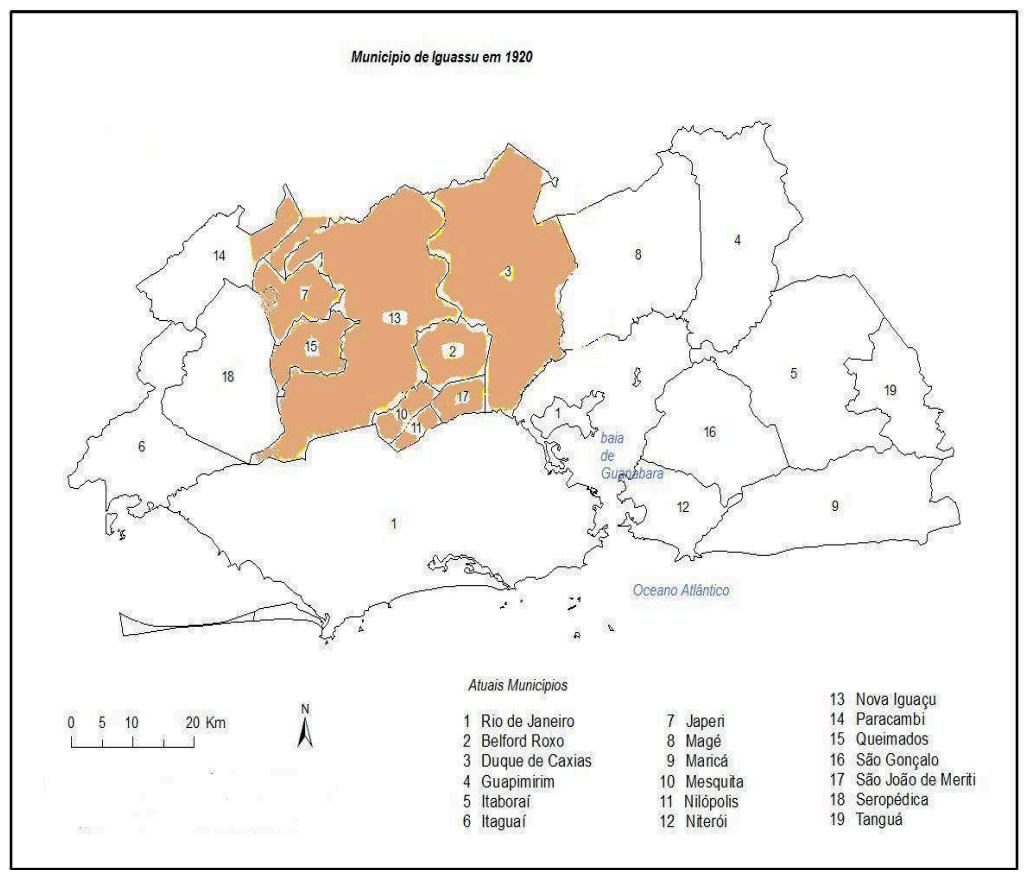

Fonte: Brasil, 1922a 


\section{Referências}

ALMANAK administrativo, mercantil e industrial da Côrte e Província do Rio de Janeiro para 0 anno de 1858. Rio de Janeiro: Typographia Eduardo e Henrique Laemmert. Disponível em: $<$ http://brazil.crl.edu/bsd/bsd/almanak/al1858/00000002.html > . Acesso em: 04 mai. 2012.

ALMANAK administrativo, mercantil e industrial da Côrte e Província do Rio de Janeiro para o anno de 1866. Rio de Janeiro: Typographia Eduardo e Henrique Laemmert. Disponível em: http://brazil.crl.edu/bsd/bsd/almanak/al1866/00000002.html. Acesso em: 04 mai. 2012 .

ALVES, José Claudio Souza. Dos barões ao extermínio: uma história da violência na baixada Fluminense. Duque de Caxias, RJ: APPH/CLIO, 2003.

CÂMARA MUNICIPAL DE NOVA IGUAÇU. Ata da sessão de 05 de novembro de 1919. Livro 2.

BRASIL. Coleção de Leis do Brasil. Império. Lei de 1 de outubro de 1828. Disponível em: $<$ http://www.planalto.gov.br/CCIVIL 03/LEIS/LIM/LIM-1-10-1828.html>. Acesso em: 14 mai. 2012

. Ministério dos Negócios do Império. Relatório apresentado à Assembleia Geral Legislativa, anno de 1871. Rio de Janeiro: Tipografia Nacional. Disponível em: <http://brazil. crl.edu/bsd/bsd/u1698/000002.html> Acesso em: 15 abr. 2012

. Diretoria Geral de Estatística. População Recenseada em 31 de dezembro de 1890. vol.4. Rio de Janeiro: Oficina de Estatística. 1898 Disponível em: <http://biblioteca.ibge. gov.br/visualizacao/livros/liv25487.pdf> Acesso em: 30 mai. 2012.

. Diretoria Geral de Estatística. População Recenseada em 1 de setembro de 1920.

Rio de Janeiro: Typ. da Estatística. 1922A. Disponível em: <http://biblioteca.ibge.gov.br/ visualizacao/livros/liv6462.pdf $>$ Acesso em: 30 mai. 2012.

. Ministério de Obras e Viação. Relatório apresentado à Assembleia Geral Legislativa, ano 1920. Rio de Janeiro: Tipografia Nacional, 1922b. Disponível em: $<$ http://brazil.crl.edu/ bsd/bsd/u2290/000002.html>. Acesso em: 15 abr. 2012.

CARDOSO, E. Nilópolis de Hontem e hoje. Nilópolis: L\& J Berkowtiz, 1938.

GOUVEA, Maria de Fátima. O império das províncias: o Rio de Janeiro 1822-1889. Rio de Janeiro: Civilização Brasileira, 2008.

HERSCHMANN, Micael; KROPF, Simone; NUNES, Clarice. Missionários do progresso: médicos, engenheiros e educadores no Rio de Janeiro - 1870- 1937. Rio de Janeiro: Diadorim, 1996.

MATOS, S. H. de. Iguaçu e sua citricultura. Rio de Janeiro: Gráfica da Bolsa, 1933.

MOREIRA, G A C. Negociantes e política local na província do Rio de Janeiro. In: SIMPÓSIO NACIONAL ESTADO E PODER: CULTURA, 6, 2010, Aracajú Anais... Aracaju: UFS/ NUPEP, 2010.

PEREIRA, W. A mudança da vila: história iguaçuana. Duque de Caxias: Arsgrafica/IHGNI, 1970. 
OLIVEIRA, C. H. de S. Tramas Políticas, redes de negócios. In: JANCSÓ, István. (Org.) Brasil: formação do Estado e da Nação. São Paulo. Hucitec/Fapesp, 2003.

PIÑEIRO, Théo Lobarinhas. As classes sociais na construção do Império do Brasil. In: MENDONÇA, S. R. de (Org). Estado e historiografia no Brasil. Niterói: UFF, 2006

RIO DE JANEIRO. Relatório do Presidente de província do Rio de Janeiro, ano de 1835, apresentado à Assembleia Legislativa. Nictheroy, Typ. de Amaral \& Irmão, 1850. Disponível em: < http://brazil.crl.edu/bsd/bsd/768/000003.html> . Acesso em: 25 abr.2012.

Relatório do Presidente de província do Rio de Janeiro, ano de 1836, apresentado à Assembleia Legislativa. Disponível em: <http://brazil.crl.edu/bsd/bsd/u815/000001.

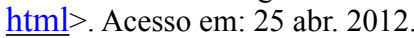

Relatório do Presidente de província do Rio de Janeiro, ano de 1837, apresentado à Assembleia Legislativa. Disponível em: $<$ http://brazil.crl.edu/bsd/bsd/u816/000001

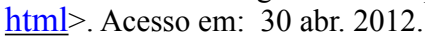

. Relatório do Presidente de província do Rio de Janeiro, ano de 1840, apresentado à Assembleia Legislativa. Segunda edição. Nictheroy, Typ. de Amaral \& Irmão, 1851. Disponível em: $<$ http://brazil.crl.edu/bsd/bsd/771/000001.html> . Acesso em: 25 abr.2012.

Relatório do Presidente de província do Rio de Janeiro, ano de 1857, apresentado à Assembleia Legislativa. Rio de Janeiro: Typ Universal Laemmert. Disponível em: $<\underline{\text { http:// }}$ brazil.crl.edu/bsd/bsd/u835/000002.html> Acesso em: 25 abr. 2012.

Relatório do Presidente de província do Rio de Janeiro, ano de 1870, apresentado à Assembleia Legislativa. Rio de Janeiro: Typ Nacional. 1870. Disponível em: <http://brazil. crl.edu/bsd/bsd/801/000002.html> . Acesso em: 25 abr. 2012.

. Relatório do Presidente de província do Rio de Janeiro, ano de 1871, apresentado à Assembleia Legislativa. Rio de Janeiro: Typ Quirino e irmãos. 1871. Disponível em: $<\underline{\mathrm{http}: / /}$ brazil.crl.edu/bsd/bsd/850/000002.html> . Acesso em: 25 abr.2012.

Mensagem do Presidente do Estado do Rio de Janeiro, ano de 1920, apresentado à Assembleia Legislativa. Rio de Janeiro, 1920. Disponível em: $<\underline{\text { http://brazil.crl.edu/bsd/bsd/ }}$ u889/000002.html> . Acesso em: 05 mar.2012

SANTOS, Luis Antônio de Castro; FARIA, Lina Rodrigues de. A reforma Sanitária no Brasil: ecos da primeira república. Bragança paulista: EDUSF, 2003.

S/A. Traços Biográficos do Comendador Soares. Rio de Janeiro: Typografia Commercial, 1874.

SILVA, Lúcia. Memórias do urbanismo na cidade do Rio de Janeiro 1778-1878: estado, administração e práticas de poder. Rio de Janeiro: E-papers, 2012.

TELLES, Pedro Carlos da S. História da Engenharia no Brasil: séculos XVI a XIX Rio de Janeiro. Rio de Janeiro: Clavero, 1994. (2 vols).

TORRES, Gênesis. (Org). Baixada Fluminense: a construção de uma história, sociedade, economia e política. São João de Meriti: IPAHB, 2004. 
SILVA, L. H. P. Saneamento e política na Baixada Fluminense: Nova Iguaçu no início do século XX.

Submissão: $26 / 08 / 2014$

Aceite em: 29/08/2014

Lúcia Silva é doutora em História Social ( PUC/SP), com Pós-doutorado em Planejamento Urbano (IPPUR/UFRJ). Docente permanente do Programa de Pós-graduação em Desenvolvimento Territorial e Políticas Publicas (PPGDT/ UFRRJ). Endereço para correspondência: Av. Gov Roberto da Silveira, S/N, Bloco ADM, sala 207, Campus Nova Iguaçu, Rio de Janeiro, Brasil. E-mail: luciahelena.silva@pq.cnpq.br 